\title{
Chargeability of Porous Rocks With or Without Metallic Particles
}

\author{
A. Revil ${ }^{1}$, T. Tartrat ${ }^{1}$, F. Abdulsamad ${ }^{1}$, A. Ghorbani ${ }^{2}$, and A. Coperey ${ }^{1}$
}

ABSTRACT

\begin{abstract}
The chargeability of rocks defines their ability to reversibly store electrical charges at low frequency (typically below a few $\mathrm{kHz}$ ). We consider the case of an isotropic mixture of metallic particles embedded into a polarizable porous background composed of mineral grains and pore water. The term metallic is here used in a broad sense involving semiconductors (for instance disseminated pyrite or magnetite), semimetals (e.g., graphite), and metals (copper, steel). The chargeability of such a mixture depends on the chargeability of the background material and the volumetric amount of metallic particles. The chargeability of the background material is in turn salinity dependent and is equal to a universal dimensionless number $R=0.08$ (ratio between the normalized chargeability and the surface conductivity) at low salinities. It is given by the ratio of two apparent mobilities, which are actually related to the mobility of the
\end{abstract}

Stern and diffuse layers forming the so-called electrical double layer around the mineral grains. This universal number is saturation and temperature independent. The predictive model for the chargeability of the mixture is compared successfully to variety of experimental and field data. We show that the polarization of dispersed metallic particles is due to the electrodiffusion of the charge carriers inside these particles. This work can be applied to conventional well-log analysis using the dispersion of the electrical conductivity with the frequency in order to determine the formation properties and accounting for the presence of pyrite in some formations. Our conductivity model appears as an extension of the Waxman and Smits seminal model of shaly sands extending this model to determine the chargeability and the effect of pyrite on both the electrical conductivity and the chargeability.

\section{INTRODUCTION}

Induced polarization reflects the ability of porous media to store reversibly electrical charges below a few kiloHertz. Schlumberger (1920) developed induced polarization as an operative geophysical method. Since, this method has found numerous applications in the field of hydrogeophysics and environmental geophysics (Kemna et al., 2012), to study the presence of pyrite over oil traps (Veeken et al., 2009; Flekkøy, 2013), and to interpret downhole measurements (Vinegar and Waxman, 1984) since induced polarization has been observed to be connected to the shaliness of the formations (Sill, 1964; Snyder et al., 1977). Along this last point, well logs of the conductivity, the dispersion of the conductivity itself (using the variation of conductivity over two distinct frequencies, the so-called percentage frequency effect, see Vinegar and Waxman, 1984), the density log and the photoelectric $\log$ (measuring the photoelectric absorption factor) can be used in concert to determine the quantity of pyrite and the transport properties of the matrix and its pore water (e.g., the salinity of the pore water, the shaliness of the formation, the permeability).

The ability of rocks to store electrical charges is described by a dimensionless material property called the chargeability $M$. Recently, models have been developed to comprehend the chargeability of porous media with and without dispersed metallic particles (see Revil et al., 2017a, b, c, and also Abdulsamad et al., 2017, for numerical modeling; and Gurin et al., 2015; 2018, for experimental data).

In this paper, we present a simple yet accurate approach to model the chargeability of porous rocks, which can be considered as a mixture of nonmetallic grains saturated by some pore water (the background) and metallic particles. The model describing the conductivity and the chargeability of the background is consistent with the Waxman and Smits (1968) equation for the electrical conductivity and the dynamic Stern-layer model of polarization of grains presented by Vinegar and Waxman (1984) in absence of metallic particles. This composite model is tested against a variety of experimental data (both new and from the literature) and discussed in terms of simple physics. Our goal

Manuscript received by the Editor March 14, 2018; revised manuscript received May 13, 2018; manuscript accepted July 3, 2018.

${ }^{1}$ Univ. Grenoble Alpes, Univ. Savoie Mont Blanc, CNRS, IRD, IFSTTAR, ISTerre, 38000 Grenoble, France; andre.revil@univ-smb.fr; tartrattimothe@gmail.com; feras.abdul-samad@univ-smb.fr; antoine.coperey@gmail.com.

2Department of Mining and Metallurgical Engineering, Yazd University, Yazd, Iran; ah.ghorbani@yahoo.fr. 
is to keep the model simple enough to be used to interpret downhole measurements in a future study.

\section{DEFINITION}

The ability of a rock to store electrical charges can be described in terms of a simple rock property called chargeability. This property is dimensionless and should not be confused with another property called normalized chargeability, which has the dimension of conductivity, as discussed below. While this terminology is perhaps confusing, it has been adopted in the literature and we keep it in the present paper. We first assume that a primary current $\mathbf{J}_{p}$ is injected in the ground through two current electrodes A and B. We assume furthermore that this current has been applied from time $-T$ to time zero ( $T$ denotes the period). If we assume that $T$ is larger than the distribution of relaxation times of the rock, the secondary current builds up according to by (Seigel, 1959),

$\mathbf{J}_{S}=-M \mathbf{J}_{p}$ and $\mathbf{J}_{p}=\sigma_{0} \mathbf{E}$

where $M$ describes the chargeability, $\sigma_{0}$ denotes the DC conductivity, i.e., the conductivity observed in steady state conditions of the application of an external electrical field $\mathbf{E}$.

In this paper, we are interested in the case corresponding to the type of composite shown in Fig. 1. We consider that the background material is isotropic as well as the distribution of metallic particles; for instance, we do not consider highly elongated grains occurring in specific directions (see Wong and Strangway, 1981, and recently Gurin et al., 2018, for tackling the effect of anisotropy in the context of induced polarization of dispersed metallic particles). We consider a rock material composed by metallic particles (here we use the term "metallic" in a broad sense, including semiconductors, semimetals, and metals) embedded into a porous matrix formed by nonmetallic mineral grains saturated by some pore water.

The low-frequency polarization of rocks finds its root into the local accumulation of charges at the grain scale. Figure 2 shows the polarization of a nonmetallic particle coated by an electrical double layer composed of a Stern layer of weakly or strongly sorbed counterions and a diffuse layer. The instantaneous conductivity $\sigma_{\infty}$ corresponds to the conductivity right after the application of the external electrical field $\mathbf{E}$. At this time, all the charge carriers are mobile (polarization has not yet occurred). The polarization of the grain corresponds to the accumulation of the charge carriers at one end of the grain in the direction of the electrical field. It takes a time constant $\tau$ to fully polarize the grain and this time constant depends naturally on the square of the size of the grain (strictly speaking, $\tau$ is the relaxation time for the grain to go back to its equilibrium state when the grain has been fully polarized and the external electrical field is removed). When concentration gradients are fully established and if the applied electrical field (or current) is shut down, these accumulated charges can go back to their initial equilibrium state by electrodiffusion (i.e., their motion is driven by electrochemical potential gradients).

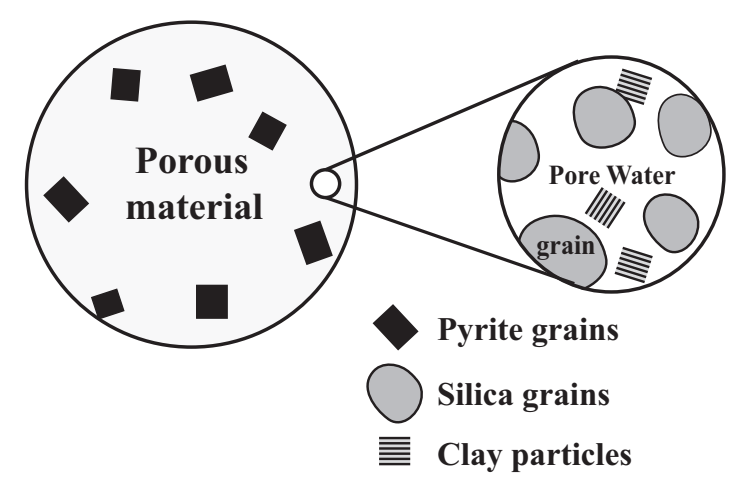

Fig. 1-Type of isotropic composite used in the present study. The background material is made of the nonmetallic grains and pore water and is polarizable. The chargeability of the mixture is increased by the presence of dispersed metallic particles. Our goal is to describe the chargeability of such mixtures as a function of the properties of the background and the volume fraction of metallic conductors.
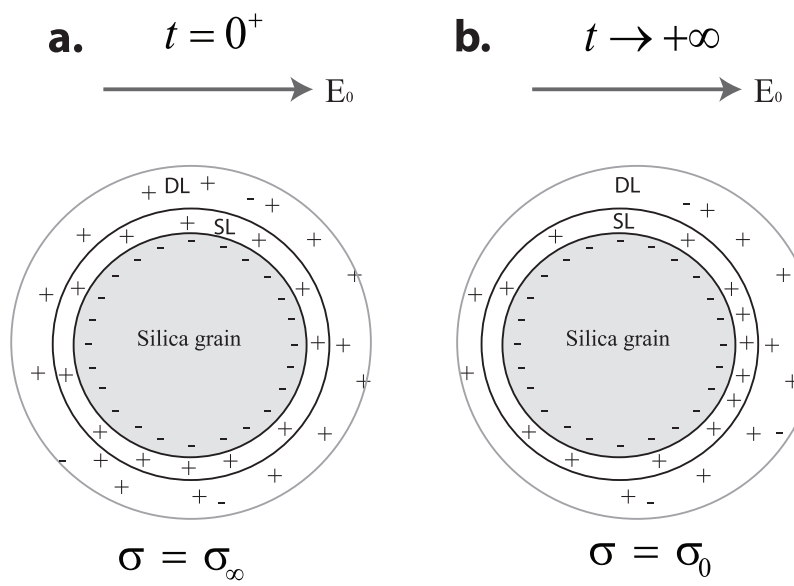

Fig. 2-Polarization of a nonmetallic grain (for example belonging to the background material shown in Fig. 1) coated by an electrical double layer. This electrical double layer is composed of a diffuse layer (DL) and a Stern layer (SL) of weakly sorbed counterions that are mobile along the grain surface. (a) Just after the application of the primary electrical field $\mathbf{E}_{0}$, all the charge carriers are mobile (both in the pore water and in the electrical double layer). The instantaneous conductivity is $\sigma_{\infty}$. (b) If the primary electrical field is applied for a long time, the conductivity is reduced to $\sigma_{0}=\sigma_{\infty}(1-M)$, where $M$ stands for the chargeability of the material (dimensionless). Some of the charge carriers (those of the Stern layer) are now blocked at the edge of the grain in the direction of the electrical field. As the result, the conductivity of the material is reduced and therefore $\sigma_{0} \leq \sigma_{\infty}$. 
When the external electrical field has been applied for a long time $(t>>)$ the grain is fully polarized and some of the charge carriers are now blocked at the edge of the grain. This means that the DC (direct current) conductivity $\sigma_{0}$ is necessarily smaller than the instantaneous conductivity $\sigma_{\infty}$. Therefore, because of the polarization of the electrical double layer, the conductivity of rocks is dispersive, i.e., it depends on the frequency. Note that another mechanism of induced polarization exists, namely the membrane polarization (Marshall and Madden, 1959). That said, this mechanism cannot explain the observed dependence of the magnitude of polarization with the salinity (see Niu et al., 2016, for a model of salinity dependence using the dynamic Stern-layer concept).

A similar process exists in dispersed metallic particles but the polarization mechanism is quite distinct (Fig. 3). Two mechanisms play a role. First, we can observe the formation of diffuse layers induced by the application of the external electrical field. In addition, the particle itself is expected to polarize due to the electromigration and diffusion of its charge carriers ( $p$-hole and electrons). Like for the case shown in Fig. 2, the DC conductivity is smaller than the instantaneous conductivity because some electrical charges have lost their mobility and are now blocked by the process of polarization in and around the metallic particles.


Fig. 3-Polarization of a metallic grain. (a) We consider a metallic particle immersed into a nonpolarizable background material in which the charge carriers are ions. Just after the application of the external electrical field $\mathbf{E}_{0}$, all the charge carriers inside (electrons and p-holes) and outside (cations and anions) of the metallic particle are mobile providing the instantaneous conductivity $\sigma_{\infty}$. The metallic particle appears highly conductive. (b) For a very long application of the external electrical field ( $t>>_{\mathrm{T}}$ where $\mathrm{T}$ is the main relaxation times of the system), the metallic particle is entirely polarized and appears as an insulator (i.e., the charge carriers are not mobile anymore). Typically the application of an electrical field for few seconds is enough to reach steady-state conditions. The generated surface charges are responsible for the formation of field-induced electrical diffuse layers (DLs) in the vicinity of the metallic particle creating also a second source of polarization. This situation defined the DC conductivity of the material $\sigma_{0} \leq \sigma_{\infty}$.
The chargeability can also be defined in terms of the characteristic of the conductivity-dispersion curve as (Seigel, 1959)

$M=\frac{\sigma_{\infty}-\sigma_{0}}{\sigma_{\infty}}$

There are also other ways to determine the chargeability based on the secondary voltage decay after the shutdown of the primary current or using the relationships that can be established in some circumstances between the chargeability and the phase (Shuey and Johnson, 1973; Revil et al., 2017a). The phase is determined from the time delay between the current and voltage time variations in frequency-domain induced polarization.

\section{A SIMPLE CHARGEABILITY MODEL}

\section{Chargeability of the Mixture}

We consider first the case shown in Fig. 1, without oxidation-reduction reactions at the interface between the metallic particles and the background material (see Wong, 1979, for a redox-controlled induced polarization mechanism). The chargeability $M$ entering Eq. 1 is directly related to the (dimensionless) volume content of metallic particles $\varphi_{m}$ (Revil et al., 2015a, see their Eqs. 69 and 70) by,

$M=1-\left(1-\frac{9}{2} \varphi_{m}\right)\left(1-M_{b}\right)$,

$M \approx \frac{9}{2} \varphi_{m}+M_{b}$,

where $M_{b}$ (dimensionless) denotes the chargeability of the background material. In absence of background polarization, we have $M_{b}=0$. According to Eq. 4 , the chargeability of the mixture is simply the sum of two contributions, one associated with the volumetric content of metallic particles, and therefore independent on pore water saturation and temperature, and a second contribution directly associated to the chargeability of the background. This second contribution is saturation and salinity dependent but independent of the temperature (see Revil et al., 2017a).

We can also go one step further and provide expressions for the instantaneous and DC conductivity of the mixture shown in Fig. 1. The instantaneous and the steady-state conductivities $\sigma_{\infty}$ and $\sigma_{0}$ are related to the instantaneous $\left(\sigma_{b}^{\infty}\right)$ and steady state $\left(\sigma_{b}^{0}\right)$ conductivities of the background material (subscript b) according to (Revil et al., 2015a, b),

$$
\begin{aligned}
& \sigma_{\infty} \approx \sigma_{b}^{\infty}\left(1+3 \varphi_{m}+\ldots\right), \\
& \sigma_{0} \approx \sigma_{b}^{0}\left(1-\frac{3}{2} \varphi_{m}+\ldots\right) .
\end{aligned}
$$


To go further, we need to express the properties of the background material first (i.e., $\sigma_{b}^{\infty}$ and $\sigma_{b}^{0}$ ), which is achieved in the next section.

\section{Chargeability of the Background Material}

A simplified circuit describing the polarization of the background material can be found in Fig. 4. The conductivity is formed by two resistors in parallel, one representing the conduction in the bulk pore space and the second representing the conduction in the electric double layer coating the surface of the grains. This circuit appears as an extension of the circuit described at high frequencies by Vinegar and Waxman (1984). The polarization and the conductivity dispersion are related to each other by the famous Kramers-Kroning relationships. They are given by the frequency dependence of the surface conductivity. The Warburg capacitance shown in Fig. 4 is used for the nonmetallic grains because the electrical double layer of these grains behaves as a leaking capacitance (it leaks some charges during the polarization process, see detailed discussion in Revil et al., 2014b).

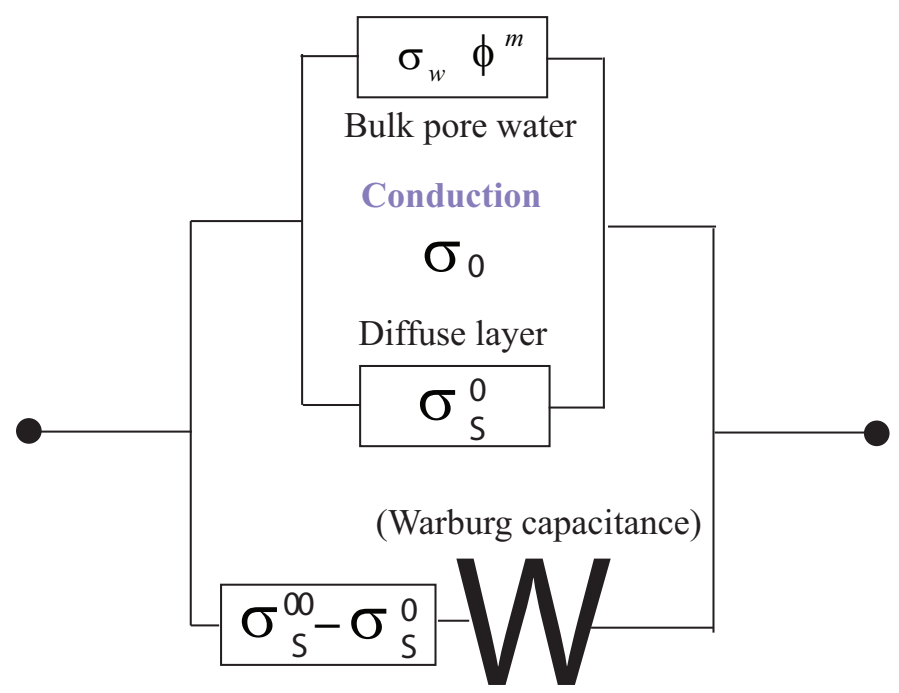

Stern layer

Polarization

Fig. 4-Equivalent circuit of the background material. The conduction process corresponds in first approximation to two resistances in parallel, one corresponding to the conduction in the bulk pore water and one associated with conduction on the electrical double layer. The Stern layer provides another additional conductivity and is responsible for the polarization of the material. The Warburg capacitance is used to model the Stern layer as a leaking capacitance (adapted from Revil et al., 2017a). The quantities $\sigma_{s}^{\infty}$ and $\sigma_{s}{ }^{0}$ denote the instantaneous and DC surface conductivity for the nonmetallic grains.
The chargeability of the background is defined as the ratio between the normalized chargeability (in $\mathrm{S} \mathrm{m}^{-1}$ ) of the background, $M_{n}^{b}$, and the instantaneous conductivity of the background material $\sigma_{\infty}^{b}$ :

$M_{b}=\frac{M_{n}^{b}}{\sigma_{\infty}^{b}}$,

$M_{n}^{b}=\sigma_{\infty}^{b}-\sigma_{0}^{b}=\sigma_{S}^{\infty}-\sigma_{S}^{0}$,

where the quantities $\sigma_{S}^{\infty}$ and $\sigma_{S}^{0}$ denote the instantaneous and DC surface conductivity (see Fig. 4). According to the dynamic Stern-layer model developed by Revil (2012; $2013 \mathrm{a}, \mathrm{b}$ ), the normalized chargeability and instantaneous conductivity of the background material can be written as (Revil et al., 2017a),

$M_{n}^{b}=\frac{1}{F \phi} \rho_{g} \lambda \mathrm{CEC}$,

$\sigma_{\infty}^{b}=\frac{1}{F} \sigma_{w}+\frac{1}{F \phi} \rho_{g} B \mathrm{CEC}$.

where $\sigma_{w}$ (in $\mathrm{S} \mathrm{m}^{-1}$ ) denotes the pore water conductivity, $\phi$ is the connected porosity (dimensionless), $F$ (dimensionless) the intrinsic formation factor, is the grain density (in $\mathrm{kg} \mathrm{m}^{-3}$, typically $\rho_{g}=2,650 \mathrm{~kg} \mathrm{~m}^{-3}$ for sedimentary rocks), and CEC is the cation exchange capacity (in $\mathrm{C} \mathrm{kg}^{-1}$ ) of the background material, which can be easily independently determined using a titration experiment (e.g., with the cobalthexamine method). The last term of Eq. 10 , i.e., $\sigma_{S}^{\infty}=\rho_{g} B C E C / F \phi$, corresponds to the so-called surface conductivity. In Eq. 10, $B$ (in $\mathrm{m}^{2} \mathrm{~s}^{-1} \mathrm{~V}^{-1}$ ) denotes the apparent mobility of the counterions for surface conduction. This parameter is close to the mobility $B$ introduced by Waxman and Smits (1968) for the in-phase conductivity (see Appendix 1). The parameters $\lambda$ (in $\mathrm{m}^{2} \mathrm{~s}^{-1} \mathrm{~V}^{-1}$ ) denotes the apparent mobility of the counterions for the polarization associated with the quadrature conductivity ( $\lambda$ is close to the apparent mobility introduced by Vinegar and Waxman, 1984, for the quadrature conductivity). We can define a dimensionless number $R=\sigma_{S}^{\infty} / M_{n}^{b}$ (i.e., the ratio of surface conductivity by the normalized chargeability). By taking the expressions of the surface conductivity and normalized chargeability of the background material, we have $R=\lambda / B$, which appears as a fundamental dimensionless number of the induced-polarization problem. We can show (while this is not the goal of the current manuscript) that $R$ is independent of the temperature and salinity).

From Eqs. 8, 9, and 10, the DC conductivity of the background material can be written as,

$\sigma_{0}^{b}=\frac{1}{F} \sigma_{w}+\frac{1}{F \phi} \rho_{g}(B-\lambda) \mathrm{CEC}$. 
Finally, an expression of the chargeability of the background material can be obtained using Eqs. 7 to 10:

$M_{b}=\frac{\rho_{g} \lambda \mathrm{CEC}}{\phi \sigma_{w}+\rho_{g} B \mathrm{CEC}}$.

At low salinities, when surface conductivity dominates the pore water conductivity, we obtain the simplified result,

$\lim _{\sigma_{w}<\frac{\rho_{g} B \mathrm{CEC}}{\phi}} M_{b}=\frac{\lambda}{B}=R$.

This means that there is a universal value for the limit of the chargeability at low salinities. From Eqs. 5,6, 10, and 11, we can easily define general expression for the instantaneous and DC conductivity of the mixture shown in Fig. 1. In the next section, we compare the previous model to a set of experimental data that have been shown to be consistent this model. Note that surface conductivity can be small but exists for all minerals in contact with water including clean sandstones (e.g., Revil et al., 2014a) and carbonates. From recent studies, we have $B\left(\mathrm{Na}^{+}, 25^{\circ} \mathrm{C}\right)=1.63 \times 10^{-8} \mathrm{~m}^{2} \mathrm{~s}^{-1} \mathrm{~V}^{-1}$ and $\lambda\left(\mathrm{Na}^{+}, 25^{\circ} \mathrm{C}\right)=1.41 \times 10^{-9} \mathrm{~m}^{2} \mathrm{~s}^{-1} \mathrm{~V}^{-1} \mathrm{~m}^{2} \mathrm{~s}^{-1} \mathrm{~V}^{-1}$ so $R=0.09$.

\section{COMPARISON WITH EXPERIMENTAL DATA}

\section{Typical Experimental Setup}

There are various experimental results reported in the next subsection. For our experiments, we use the ZEL-SIP04-V02 impedance meter (frequency-domain measurements, see Fig. 5) developed by Egon Zimmermann at the Central Laboratory for Electronics, ZEL, the Forschungszentrum Julich (see Zimmermann et al., 2008). Benchmark tests for this equipment can be found, for instance, in Revil and Skold (2011). The typical accuracy of this high-precision impedance meter is $0.1 \mathrm{mrad}$ between $1 \mathrm{mHz}$ and $1 \mathrm{kHz}$ and $0.4 \mathrm{mrad}$ between $1 \mathrm{kHz}$ and $45 \mathrm{kHz}$. We generally use an applied voltage of $\pm 0.2 \mathrm{~V}$ for our experiments.

The methodology used for our experiments is essentially the same as in Revil et al. (2017a) and will not be repeated here. The sample holder for the new experiment reported in this paper is made of an acrylic box in which a metallic cylindrical tube is placed normal to the direction of the applied electrical field (Fig. 5). The two current electrodes $\mathrm{A}$ and $\mathrm{B}$ are placed at the end faces of the sample holder. The background material is a calibrated silica sand $(183 \mathrm{~mm}$ for the median grain diameter, porosity $45 \%$ ) filled with tap water (conductivity at $25^{\circ} \mathrm{C} 0.06 \mathrm{~S} \mathrm{~m}^{-1}$ ). This configuration is used to impose a uniform electrical field through the sample. The two potential electrodes $\mathrm{M}$ and $\mathrm{N}$ are in contact with the sand on the side of the metallic bar. The conversion between the measured impedance into the complex conductivity was done by using a geometrical factor $K$ (in $\mathrm{m}^{-1}$ ) depending on the geometry of the electrodes $(K=L / A$ in the present case, where $A$ is the surface area of a cross section of the current electrodes and $L$ is the distance between the voltage electrodes $\mathrm{M}$ and $\mathrm{N}$ ).

In order to discriminate the mechanism at play regarding the polarization of the metallic body, we used two metallic (stainless steel) bars of the same diameter $(12 \mathrm{~mm})$. The volume fraction of metal in the sandbox is $1.3 \%$. If the polarization occurs just outside the bar, induced mainly by the polarization of the diffuse layer and potentially by redoxactive processes (see Wong, 1979; and Chu and Bazant, 2006), the relaxation time of the polarization process should be independent of the internal shape of the metallic bar since the charges are expected to relax outside the material. If the polarization process has to do with the electrodiffusion of the charge carriers inside the bar (p-holes and electrons), the tortuosity of the secondary current paths should affect the relaxation time since they affect the effective diffusion coefficient of the charge carriers. Indeed, the tortuosity associated with the diffusion of the charge carriers in the hollow tube should be substantially larger by a factor $\pi^{2} \gg 10$ than for the plain tube ( $\pi^{2}$ is obtained by taking the square of half the circumference of the tube over the tube diameter). a. Sample holder

A
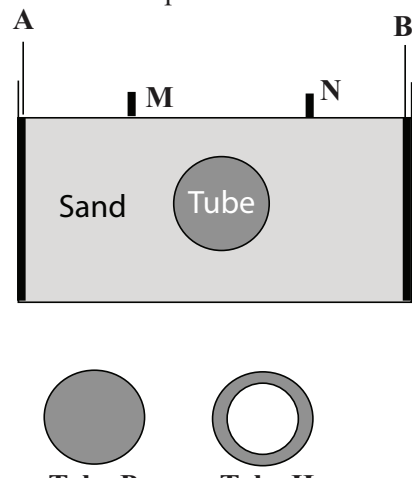

Tube P

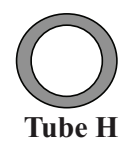

b. ZEL-SIP04-V02

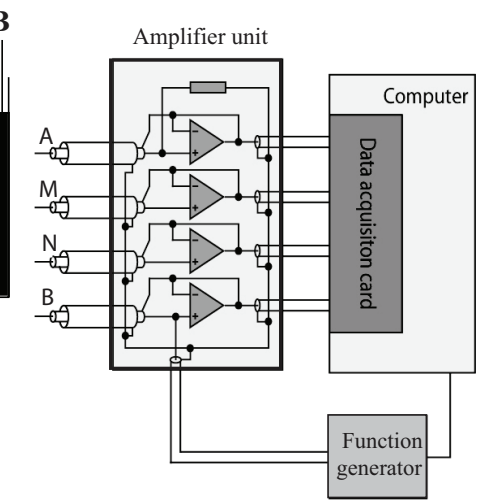

Fig. 5-Sample holder for the experiment with the two stainless steel tubes and impedance meter. (a) Sample holder filled with a tap water$\left(0.06 \mathrm{~S} \mathrm{~m}^{-1}\right)$ saturated sand in which a metallic tube is immersed. $\mathrm{P}$ denotes the plain tube while $\mathrm{H}$ denotes the hollow tube. The size of the sandbox is $17.8 \times 10.8 \times 5 \mathrm{~cm}$. (b) High-precision impedance meter. A and $\mathrm{B}$ being the current electrodes and $\mathrm{M}$ and $\mathrm{N}$ the voltage electrodes. SIP04-V02 impedance meter developed by Egon Zimmermann at the Central Laboratory for Electronics, ZEL, the Forschungszentrum Julich (Zimmermann et al., 2008).

We also performed two series of experiments in which we used the experimental setup shown in Fig. 5b and mixtures of pyrite cubes (around $1 \mathrm{~cm}$ in diameter) and either a crushed volcanic rock (porosity $0.50 \pm 0.05, \mathrm{CEC}=$ $2.48 \mathrm{meq} / 100 \mathrm{~g}$ ) or illite (porosity $0.71 \pm 0.01, \mathrm{CEC}=9.74$ $\mathrm{meq} / 100 \mathrm{~g})$. In both cases, the CEC was measured with 
the cobalthexamine method. The goal of these experiments is to check the validity of Eq. 4 . For the mixtures of illite and pyrite, the pore water conductivity is $0.10 \mathrm{~S} \mathrm{~m}^{-1}(\mathrm{NaCl}$, $25^{\circ} \mathrm{C}$ ). For the mixtures of volcanic rock and pyrite, the pore water conductivity was $0.17 \mathrm{~S} \mathrm{~m}^{-1}\left(\mathrm{NaCl}, 25^{\circ} \mathrm{C}\right)$.

\section{Tests of the model}

The properties of the background material are analyzed first using data from the literature. In Fig. 6, we plot the normalized chargeability versus the surface conductivity $\sigma_{S}^{\infty}$. The normalized chargeability is for instance determined from the dispersion of the conductivity curve over five decades (typically between $0.1 \mathrm{~Hz}$ and $10 \mathrm{kHz}$ ). The surface conductivity is determined from a conductivity plot, such as those shown by Waxman and Smits (1968), i.e., by plotting the high-frequency conductivity of the rock or porous material (without metallic particles) versus the porewater conductivity for experiments performed at different salinities and using the relationship between these two parameters $\left(\sigma_{\infty}^{b}=\sigma_{w} / F+\sigma_{S}^{\infty}\right)$ where the expression of the surface conductivity $\sigma_{S}^{\infty}$ can be found from Eq. 10 .

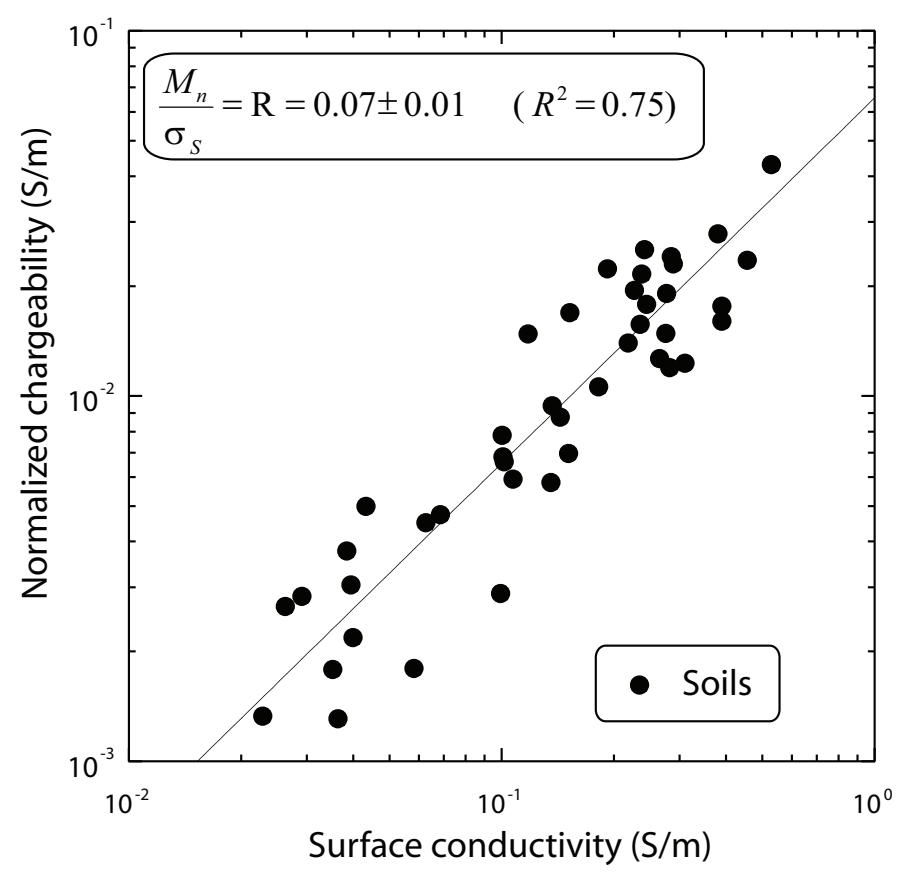

Fig. 6-Linear relationship between normalized chargeability (between $0.1 \mathrm{~Hz}$ and $40 \mathrm{kHz}$ ) and surface conductivity for the soil samples at a low-salinity pore-water conductivity of $0.03 \mathrm{~S} \mathrm{~m}^{-1}\left(\mathrm{NaCl}, 25^{\circ} \mathrm{C}\right)$. The soil data are from Revil et al. (2017a). The plain line corresponds to the best fit of the data using a linear model between the normalized chargeability and the surface conductivity. The value of the slope is equal to the value of the dimensionless number $R$.
In Fig. 6, the slope of the trend between $M_{n}$ and the surface conductivity $\sigma_{S}^{\infty}$ provides the dimensionless number $\mathrm{R}$ equal here close to $7 \pm 2 \times 10^{-2}$. In Fig. 7 , we plot the chargeability of the background as a function of the cation exchange capacity at low salinity for the same collection of soil samples plus some sandstones and sands (from Revil et al., 2018). In agreement with Eq. 13, the chargeability of the background is independent of the CEC and given by the constant $R=8 \times 10^{-2}$.

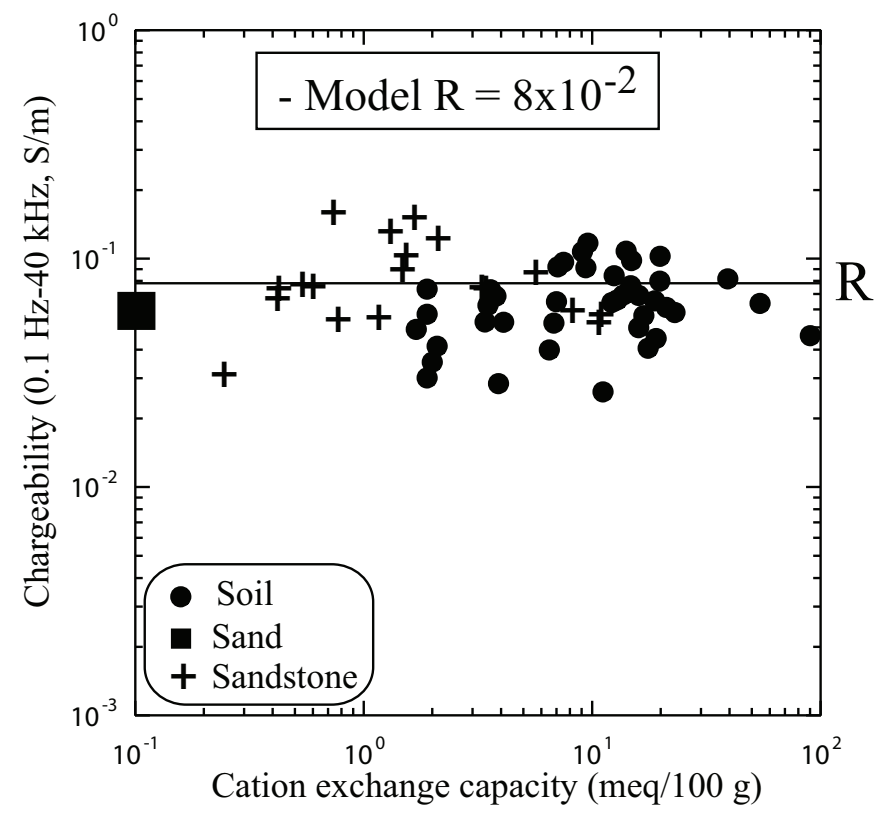

Fig. 7-Plot of chargeability versus CEC for the background material at low salinities. The sandstone data are from Vinegar and Waxman (1984) (all samples at the lowest salinity, the normalized chargeabilities are obtained using his quadrature conductivity data at $0.1 \mathrm{~S} \mathrm{~m}^{-1}$ ) and the soil and sandstone data are from Revil et al. (2017a), and Revil et al. (2018), respectively.

In Fig. 8, we plot the conductivity as a function of the frequency for a sand bentonite mix (the background) and the same mixture in which we added some pyrite grains. We see clearly that at low frequencies, the presence of pyrite decreases the conductivity of the overall mixture compared with the conductivity of the sand plus bentonite mix. This is because at low frequencies, the pyrite grains are fully polarized and are becoming insulators. At high frequencies, the opposite happens. The pyrite grains are much more conductive than the background and there is an increase of the conductivity of the mixture with respect to the conductivity of the sand + bentonite mixture. 


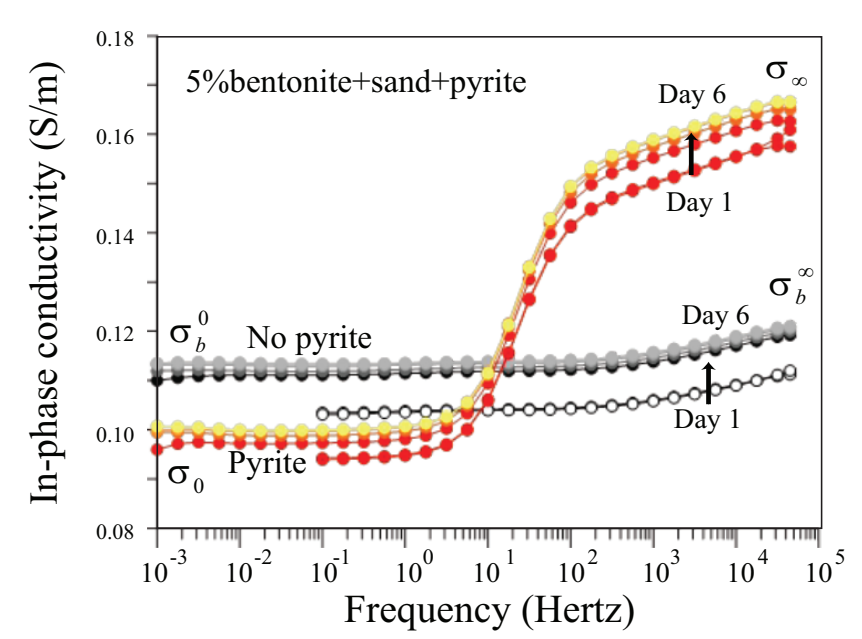

Fig. 8-Complex conductivity spectrum of a sand/bentonite mixture and complex conductivity of the same sand/bentonite mixture in which pyrite has been added. We see that at low frequencies, the conductivity of the mixture sand + bentonite + pyrite is smaller than the conductivity of the sand + bentonite mixture. This is because the pyrite grains appear as insulators at low frequencies. The opposite happens at high frequencies with the pyrite grains characterized by a much higher conductivity than the conductivity of the background. The lines are just guides for the eyes. The colors correspond to the days elapsed after the preparation of the mixtures.

Finally, Figs. 9 and 10 demonstrates the validity of Eq. 4. In Fig. 9, we plot the chargeability of some mixture of metallic grains with a background material. We see that Eq. 4 predicts very well the variations of the chargeability with the volumetric content of metallic particle.

The same is shown in Fig. 10 for a mixture of pyrite and crushed volcanic or illite material at low salinity. Not only the data checks Eq. 4, but also the background chargeability is close to the dimensionless number $R=8 \times 10^{-2}$ as predicted by the model (see Eq. 13).

Finally, in Figs. 11 and 12 we plot the phase and conductivity amplitude spectra obtained for the two stainless steel tubes of Fig. 5. The chargeability of the two tubes is roughly equal $\left(M=6.3 \times 10^{-2}\right.$ for the empty tube and 8.8 $\times 10^{-2}$ for the plain tube) and substantially higher than the chargeability of the background $\left(M_{b}=9 \times 10^{-3}\right)$. These values are also reported in Fig. 9 and are consistent with the other data described above. We clearly see that the phase peaks are very different. The relaxation times are $\tau=0.0647$ $\mathrm{s}$ for the hollow tube and are $\tau=0.0030 \mathrm{~s}$ for the plain tube using a Cole-Cole model for the complex conductivity. This indicates that the polarization process seems to be associated with the electrodiffusion of the charge carriers inside the bars themselves and favors the model developed by Revil et al. (2015a, b) over the model of Wong (1979).

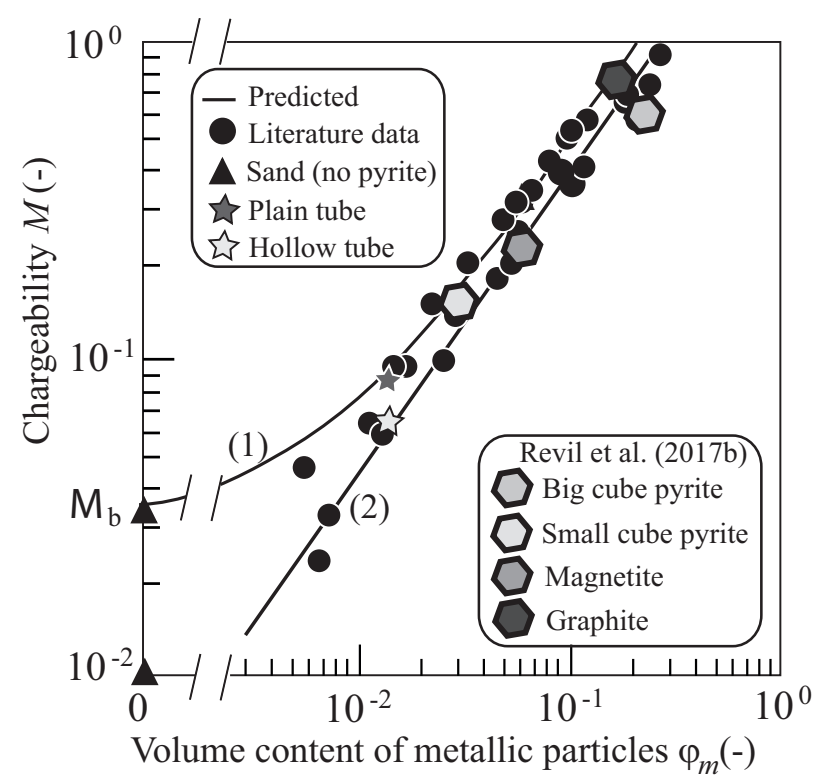

Fig. 9-Comparison between the chargeability $M$ of the mixture shown in Fig. 1 (determined at $25^{\circ} \mathrm{C}$ ) and the volume fraction of metallic particle mixed with sand and $M_{b}$ denotes the chargeability of the background. The two curves ((1) with sand background) and ((2) without background) correspond to Eq. 3, with and without background polarization, respectively (see Pelton et al., 1978; Mahan et al., 1986; Philips, 2010; Gurin et al., 2013; and Revil et al., 2017a). The chargeability of the sand (filled triangle) depends on the salinity of the pore-water electrolyte. The chargeability of the plain and hollow metallic (stainless steel) tubes in sand are determined from the experimental setup and impedance meter shown in Fig. 5.

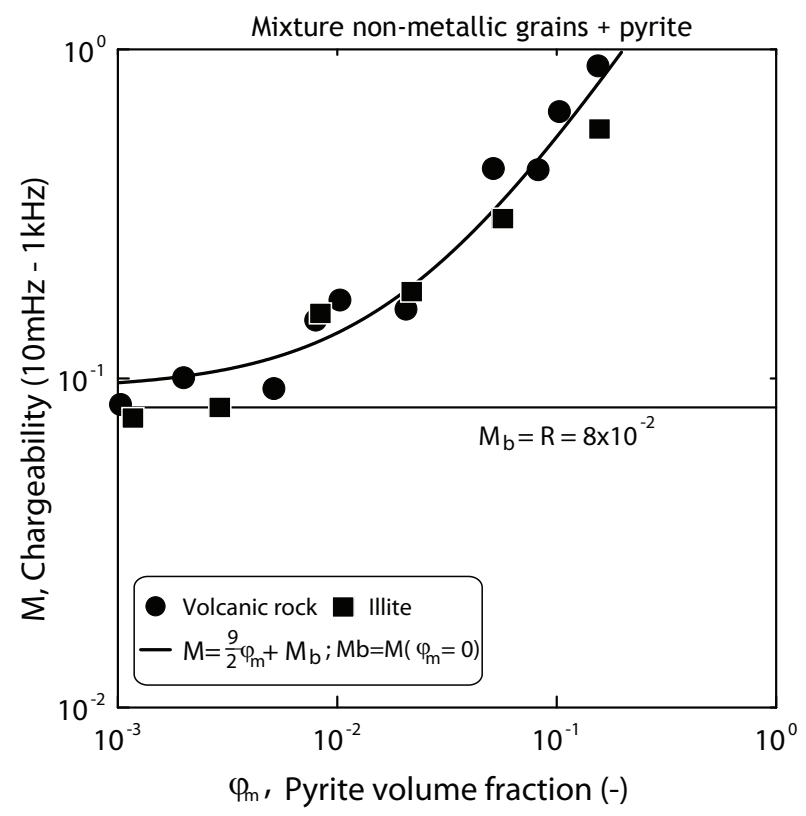

Fig. 10-Influence of the volume content of pyrite $\varphi_{m}$ on the chargeability $M$ of a mixture of nonmetallic grains (volcanic rock or illite) and pyrite. The background volcanic rock corresponds to the MERTurist core sample from Merapi volcano in Indonesia. The plain line corresponds to the prediction of the theory (no fitting parameters). Note that at low salinity, $M_{b}=R=8 \times 10^{-2}$. 


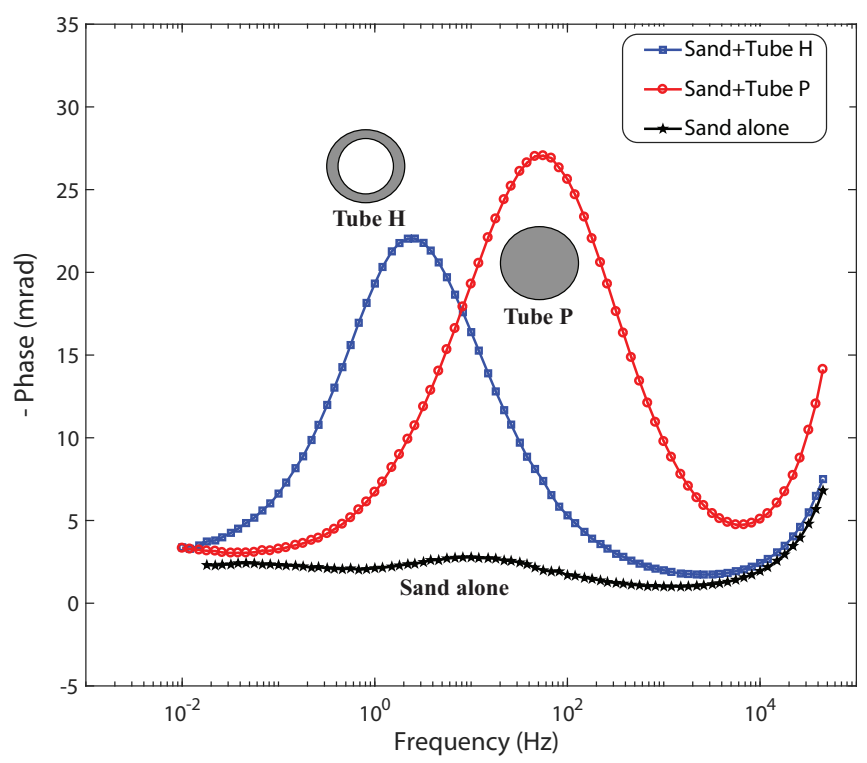

Fig. 11-Phase spectrum for the two tubes (one hollow, $\mathrm{H}$, one plain, $P)$. Note that the phase peak is different, while the diameter of the two metallic tubes remains the same. For the hollow tube, the tortuosity of the charge carriers inside the particle is larger by comparison with the case of the plain tube, explaining that the peak frequency is smaller.

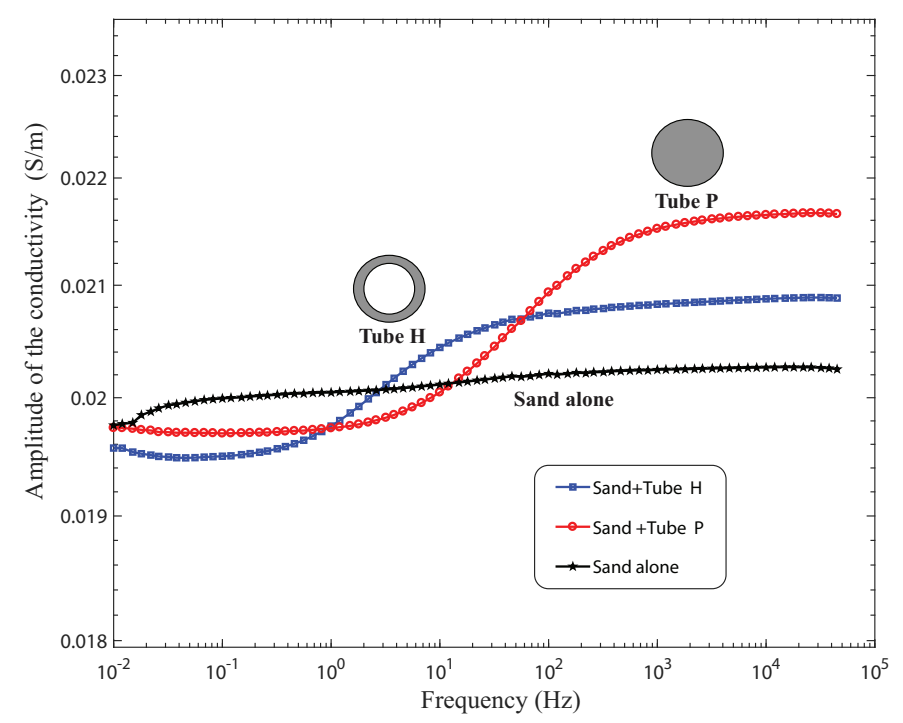

Fig. 12-Conductivity amplitude spectrum for the two tubes (one hollow, $\mathrm{H}$, one plain, $\mathrm{P})$ in the background sand. Note that at low frequencies, the conductivity of the mixture (sand + metallic tube) is smaller than the conductivity of the sand alone implying that the metallic tubes are acting as insulators in agreement with what is shown in Fig. 8 for pyrite.

\section{CONCLUSIONS}

A simple model has been built to describe the chargeability of isotropic mixtures between a porous material (background) in which is embedded metallic particles. The effective chargeability of the mixture appears to be the sum of two contributions. The first contribution is associated with the volumetric content of metallic particles. It is independent of the temperature and salinity. The second contribution corresponds to the chargeability of the background material. It is temperature independent but salinity dependent. At low salinity, this background chargeability reaches its highest value and is given by a dimensionless constant $R$, which was introduced by Revil (2012; 2013a, b). This constant (independent of temperature and salinity) can be recovered by both laboratory and field data. An experiment made with two stainless steel tubes (one hollow and one plain) shows distinct relaxation times. This provides the first demonstration (to the best of our knowledge) that the polarization of the tube is related to the polarization of the charge carriers inside the tube as suggested in Revil et al. (2015a, b).

\section{ACKNOWLEDGEMENTS}

We thank Nicolas Florsch for fruitful discussions on this subject. We also thank the two referees and the Editors Dr. Carlos Torres-Verdín and Stephen Prensky, for their time and constructive comments and for fruitful discussions.

\section{NOMENCLATURE}

$A=$ Surface area of a cross-section of the core sample $\left(\mathrm{m}^{2}\right)$

$B=$ apparent mobility of the counterions for surface conduction $\left(\mathrm{m}^{2} \mathrm{~s}^{-1} \mathrm{~V}^{-1}\right)$

$\mathrm{CEC}=$ cation exchange capacity of the background $\left(\mathrm{C} \mathrm{kg}^{-1}\right)$

$\mathbf{E}=$ electrical field $\left(\mathrm{V} \mathrm{m}^{-1}\right)$

$F=$ the intrinsic formation factor of the background (-)

$\mathbf{J}_{S}=$ secondary source current density $\left(\mathrm{A} \mathrm{m}^{-2}\right)$

$\mathbf{J}_{p}=$ primary source current density $\left(\mathrm{A} \mathrm{m}^{-2}\right)$

$\stackrel{p}{K}=$ geometrical factor of the cylindrical core sample $\left(\mathrm{m}^{-1}\right)$

$L=$ length of the core sample (m)

$M=$ chargeability of the mixture (background and metallic grains) (-)

$M_{b}=$ chargeability of the background (-)

$M_{n}=$ normalized chargeability of the mixture $\left(\mathrm{S} \mathrm{m}^{-1}\right)$

$M_{n}^{b}=$ normalized chargeability of the background $\left(\mathrm{S} \mathrm{m}^{-1}\right)$

$Q_{V}^{n}=$ excess of electrical charge per unit pore volume of the background $\left(\mathrm{C} \mathrm{m}^{-3}\right)$

$R=$ ratio of surface conductivity by the normalized chargeability (-)

$\lambda=$ apparent mobility of the ions for the polarization process of the background $\left(\mathrm{m}^{2} \mathrm{~s}^{-1} \mathrm{~V}^{-1}\right)$

$\rho_{g}=$ mass density of the solid grains of the background $\left(\mathrm{kg} \mathrm{m}^{-3}\right)$

$\sigma_{0}=$ direct current (DC) conductivity of the mixture (S $\mathrm{m}^{-1}$ ) 
$\sigma_{b}^{0}=$ direct current (DC) conductivity of the background $\left(\mathrm{S} \mathrm{m}^{-1}\right)$

$\sigma_{S}^{0}=$ direct current (DC) surface conductivity of the background $\left(\mathrm{S} \mathrm{m}^{-1}\right)$

$\sigma_{\infty}=$ instantaneous conductivity of the mixture $\left(\mathrm{S} \mathrm{m}^{-1}\right)$

$\sigma_{b}^{\infty}=$ instantaneous conductivity of the mixture $\left(\mathrm{S} \mathrm{m}^{-1}\right)$

$\sigma_{S}^{\infty}=$ instantaneous surface conductivity of the background $\left(\mathrm{S} \mathrm{m}^{-1}\right)$

$\sigma_{w}=$ pore-water conductivity $\left(\mathrm{S} \mathrm{m}^{-1}\right)$

$\tau=$ relaxation time of the polarization process (s)

$\phi=$ connected porosity (-)

$\varphi_{m}=$ volume fraction of metallic particle in the mixture $(-)$

\section{REFERENCES}

Abdulsamad, F., Florsch, N., and Camerlynck, C., 2017, Spectral Induced Polarization in a Sandy Medium Containing Semiconductor Materials: Experimental Results and Numerical Modelling of the Polarization Mechanism, Near Surface Geophysics, 15(6), 669-683. DOI: 10.3997/ 1873-0604.2017052.

Chu, K.T., and Bazant, M.Z., 2006, Nonlinear Electrochemical Relaxation Around Conductors, Physical Review E, 74, 011501. DOI: 10.1103/PhysRevE.74.011501.

Flekkøy, E.G., 2013, A Physical Basis for the Cole-Cole Description of Electrical Conductivity of Mineralized Porous Media, Geophysics, 78(5), D353-D366. DOI: 10.1190/ geo2012-0478.1.

Gurin, G., Ilyin, Y., Nilov, S., Ivanov, D., Kozlov, E., and Titov, K., 2018, Induced Polarization of Rocks Containing Pyrite: Interpretation Based on X-Ray Computed Tomography, Journal of Applied Geophysics, 154, 50-63. DOI: 10.1016/j. jappgeo.2018.04.019.

Gurin, G., Tarasov, A., Ilyin, Y., and Titov, K., 2013, Time Domain Spectral Induced Polarization of Disseminated Electronic Conductors: Laboratory Data Analysis Through the Debye Decomposition Approach, Journal of Applied Geophysics, 98, 44-53. DOI: 1016/j.jappgeo.2013.07.008.

Gurin, G., Titov, K., Ilyin, Y., and Tarasov, A., 2015, Induced Polarization of Disseminated Electronically Conductive Minerals: A Semi-Empirical Model, Geophysical Journal International, 200(3), 1555-1565. DPI: 10.1093/gji/ggu490.

Kemna, A., Binley, A., Cassiani, G., Niederleithinger, E., Revil, A., Slater, L., Williams, K.H., Orozco, A.F., Haegel, F.-H., Hördt, A., Kruschwitz, S., Leroux, V., Titov, K., and Zimmermann, E., 2012, An Overview of the Spectral Induced Polarization Method for Near-Surface Applications, Near Surface Geophysics, 10(6), 453-468. DOI: 10.3997/18730604.2012027.

Mahan, M.K., Redman, J.D., and Strangway, D.W., 1986, Complex Resistivity of Synthetic Sulphide Bearing Rocks, Geophysical Prospecting, 34(5), 743-768. DOI: 10.1111/j.1365-2478.1986. tb00491.x.

Marshall, D.J., and Madden, T.R., 1959, Induced Polarization, a Study of its Causes, Geophysics, 24(4), 790-816. DOI: 10.1190/1.1438659.

Niu Q., Revil, A., and Saidian, M., 2016, Salinity Dependence of the Complex Surface Conductivity of the Portland Sandstone, Geophysics, 81(2), D125-D140. DOI: 10.1190/ geo2015-0426.1.

Pelton, W.H., Ward, S.H., Hallof, P.G., Sill, W.R., and Nelson, P.H., 1978, Mineral Discrimination and Removal of Inductive Coupling With Multifrequency IP: Geophysics, 43(3), 588609. DOI: $10.1190 / 1.1440839$.

Phillips, C.R., 2010, Experimental Study of the Induced Polarization Effect Using Cole-Cole and Gemtip Models, unpublished MS thesis, University of Utah. http://cdmbuntu. lib.utah.edu/utils/getfile/collection/etd2/id/1088/filename/34. pdf. Accessed July 15, 2018.

Revil A., and Skold, M., 2011, Salinity Dependence of Spectral Induced Polarization in Sands and Sandstones, Geophysical Journal International, 187(2), 813-824. DOI: 10.1111/j.1365246X.2011.05181.x.

Revil, A., 2012, Spectral Induced Polarization of Shaly Sands: Influence of the Electrical Double Layer, Water Resources Research, 48(2), W02517. DOI: 10.1029/2011WR011260.

Revil, A., 2013a, Effective Conductivity and Permittivity of Unsaturated Porous Materials in the Frequency Range 1 mHz-1GHz: Water Resources Research, 49(1), 306-327. DOI: $10.1029 / 2012$ WR012700.

Revil, A., 2013b, On Charge Accumulation in Heterogeneous Porous Rocks Under the Influence of an External Electrical Field, Geophysics, 78(4), D271-D291. DOI: 10.1190/ GEO2012-0503.1.

Revil A., Abdel Aal, G.Z. Atekwana, E.A., Mao, D., and Florsch, N., 2015b, Induced Polarization Response of Porous Media With Metallic Particles-Part 2: Comparison With a Broad Database of Experimental Data: Geophysics, 80(5), D539D552. DOI: 10.1190/GEO2014-0578.1.

Revil A., Coperey, A., Deng, Y.,Cerepi, A., and Seleznev, N., 2018, Complex Conductivity of Tight Sandstones, Geophysics, 83(2), E55-E74. DOI: 10.1190/geo2017-0096.1.

Revil, A., Coperey, A., Shao, Z., Florsch, N., Fabricius, I.L., Deng, Y., Delsman, J.R., Pauw, P.S., Karaoulis, M., de Louw, P.G.B., van Baaren, E.S., Dabekaussen, W., Menkovic, A., and Gunnink, J.L. 2017a, Complex Conductivity of Soils, Water Resources Research, 53(8), DOI: 10.1002/2017WR020655.

Revil A., Florsch, N., and Camerlynck, C., 2014b, Spectral Induced Polarization Porosimetry, Geophysical Journal International, 198(2), 1016-1033. DOI: 10.1093/gji/ggu180.

Revil A., Florsch, N., and Mao, D., 2015a, Induced Polarization Response of Porous Media With Metallic Particles-Part 1: A Theory for Disseminated Semiconductors, Geophysics, 80(5), D525-D538. DOI: 10.1190/geo2014-0577.1.

Revil, A., Kessouri, P., and Torres-Verdín, C., 2014a, Electrical Conductivity, Induced Polarization, and Permeability of the Fontainebleau Sandstone, Geophysics, 79(5), D301-D318. DOI: 10.1190/geo2014-0036.1.

Revil A., Mao, D., Shao, Z., Sleevi, M.F., and Wang, D., 2017c, 
Induced Polarization Response of Porous Media With Metallic Particles-Part 6: The Case of Metals and SemiMetals, Geophysics, 82(2), E97-E110, DOI: 10.1190/ geo2016-0389.1.

Revil A., Sleevi, M.F. and Mao, D. 2017b, Induced Polarization Response of Porous Media With Metallic Particles-Part 5: Influence of the Background Polarization, Geophysics, 82(2), E77-E96, DOI: 10.1190/geo2016-0388.1.

Schlumberger, C., 1920, Etude sur la Prospection Electrique du Sous-sol [Study of Underground Electrical Prospecting], Gauthier-Villars et Cie, Paris. Reprinted in English in 2012, HardPress Publishing. ISBN: 978-1290265904.

Seigel, H.O., 1959, Mathematical Formulation and Type Curves for Induced Polarization, Geophysics, 24(3), 547-565. DOI: 10.1190/1.1438625.

Shuey, R.T., and Johnson, M., 1973, On the Phenomenology of Electrical Relaxation in Rocks: Geophysics, 38(1), 37-48. DOI: $10.1190 / 1.1440331$.

Sill, W.R., 1964, Induced Polarization in Clay-Bearing Sandstones and the Effects of Oil Saturation, Research Report, Institute of Geophysics and Planetary Science, University of California San Diego. August.

Snyder, D.D., Merkel, R.H., and Williams, J.T., 1977, Complex Formation Resistivity-The Forgotten Half of the Resistivity Log, Paper Z, Transactions, SPWLA 18th Annual Logging Symposium, Houston, Texas, USA 5-8 June.

Veeken, P., Legeydo, P., Davidenko, Y., Kudryavceva, E., Ivanov, S., and Chuvaev, A., 2009, Benefits of the Induced Polarization Geolectric Method to Hydrocarbon Exploration, Geophysics, 74(2), B47-B59. DOI: 10.1190/1.3076607.

Vinegar, H., and Waxman, M., 1984, Induced Polarization of Shaly Sands, Geophysics, 49(8), 1267-1287. DOI: 10.1190/ 1.1441756.

Waxman, M.H., and Smits, L.J.M., 1968, Electrical Conductivities in Oil Bearing Shaly Sands, Paper SPE-1863-A, SPE Journal, 8(2), 107-122. DOI: 10.2118/1863-A.

Wong, J., 1979, An Electrochemical Model of the InducedPolarization Phenomenon in Disseminated Sulfide Ores, Geophysics, 44(7), 1245-1265. DOI: 10.1190/1.1441005.

Wong, J., and Strangway, D.W., 1981, Induced Polarization In Disseminated Rocks Containing Elongated Mineralization Sulfide Ores, Geophysics, 46(9), 1258-1268. DOI: 10.1190/1.1441264.

Zimmerman, E., Kemna, A., Berwix, J., Glass, W., Münch, H.M., and Huisman, J.A., 2008, A High-Accuracy Impedance Spectrometer for Measuring Sediments With Low Polarizability, Measurement Science and Technology, 19(10), 105603. DOI: 10.1088/0957-0233/19/10/105603.

\section{APPENDIX 1: COMPARISON WITH THE WAXMAN AND SMITS MODEL}

In this appendix, we compare the equation used to model the conductivity of the background material to the Waxman and Smits (1968) equation. This equation can be written as,
$\sigma_{\infty}^{b}=\frac{1}{F}\left(\sigma_{w}+B Q_{V}\right)$,

where the excess of electrical charge per unit pore volume, $Q_{V}\left(\right.$ in $\left.\mathrm{C} \mathrm{m}^{-3}\right)$, is related to the $\mathrm{CEC}$ by,

$Q_{V}=\rho_{g} \frac{1-\phi}{\phi}$ CEC.

Equation A1.2 corresponds just to a transform of the charge per unit mass of grains (i.e., the $\mathrm{CEC}, \mathrm{C} \mathrm{kg}^{-1}$ ) to a charge per unit pore volume and $\rho_{g}$ and $\phi$ denote the grain density and the connected porosity, respectively. Using Eq. A1.2 in Eq. A1.1, we obtain,

$\sigma_{\infty}^{b}=\frac{1}{F}\left(\sigma_{w}+B \rho_{g} \frac{1-\phi}{\phi} \mathrm{CEC}\right)$,

which is similar to Eq. 10 of the main text except a factor $(1-\phi)$ in the surface conductivity. For core samples characterized by porosity less than $30 \%$, this correction factor is comprised between 1 and 0.70 , so the difference between the two equations is rather small. The equations developed in the main text can be therefore seen as providing a simple extension to the Waxman and Smits (1968) formula in presence of pyrite. 